Lung Maturation and the Prevention of Hyaline Membrane Disease. Report of the 70th Ross Conference on Pediatric Research. Ross Laboratories, Columbus, OH, pp 37-40

19. Kotas RV, Avery ME 1971 Accelerated appearance of pulmonary surfactant in the fetal rabbit. J Appl Physiol 30:358-361

20. Lorenzo AV, Welch K, Conner S 1982 Spontaneous germinal matrix and intraventricular hemorrhage in prematurely born rabbits. J Neurosurg 56:404-410

21. Mims LC 1979 Adaptive gluconeogenesis in preterm and term rabbits. Pediatr Res 13:241-245

22. Myers RE 1975 Maternal psychological stress and fetal asphyxia: A study in the monkey. Am J Obstet Gynecol 122:47-59

23. Nilsson R 1979 Lung compliance and lung morphology following ventilation in the premature and full term rabbit neonate. Scand J Resp Dis 60:206214
24. Pape KE, Wigglesworth JS 1979 Hemorrhage, Ischemia and the Perinatal Brain. Spastics International Medical Publications, London

25. Reynolds ML, Evans CAN, Saunders NR, Reynolds EOR, Wigglesworth JS 1977 Intracranial hemorrhage in sheep fetus. Pediatr Res 11:1024-1029

26. Ruppenthal GC 1977 Survey of protocols for nursery rearing macaques. In: Ruppenthal GC, Reese DJ (eds) Nursery Care of Nonhuman Primates. Plenum Press, New York, pp 165-185

27. Shnider SM, Biehl DR 1981 The effect of maternal stress and general anesthesia on plasma catecholamines and uterine blood flow in the pregnant ewe. In: Stern L, Salle B, Friis-Hansen B (eds) Intensive Care in the Newborn, III. Massen Publications Inc, New York, pp 31-38

28. Sokal M, Sinclair J 1976 Effect of temperaure on growth of newborn rabbits. Biol Neonate 28:1-11

29. van Marthens E, Harel S, Zamenhof S 1975 Experimental intrauterine growth retardation. Biol Neonate 26:221-231

\title{
Phototherapy for Neonatal Jaundice: in Vivo Clearance of Bilirubin Photoproducts
}

\author{
JOHN F. ENNEVER, ISABELLA KNOX, SCOTT C. DENNE, AND WILLIAM T. SPECK \\ Department of Pediatrics, Rainbow Babies and Childrens Hospital, Case Western Reserve University School of \\ Medicine, Cleveland, Ohio
}

\begin{abstract}
Phototherapy results in the conversion of native bilirubin to more water-soluble configurational and structural isomers. The serum half-life for the configurational isomer, the principal photoproduct in vivo, was determined by high pressure liquid chromatography in six premature infants following cessation of phototherapy. The mean half-life for this isomer was $15 \mathrm{~h}$. The excretion of this isomer, calculated from the measured half-life, is less than half of daily bilirubin production, and therefore cannot account for the total bilirubin elimination observed during phototherapy. The serum concentration of the structural isomer, lumirubin, is lower than that of the configurational isomer; however, excretion is more rapid (serum half-life $<2 \mathrm{~h}$ ). Because of its rapid excretion, lumirubin may be an important pathway for bilirubin elimination during phototherapy. (Pediatr Res 19: 205-208, 1985)
\end{abstract}

\section{Abbreviation}

HPLC, high pressure liquid chromatography

Despite the widespread use of phototherapy in the treatment of neonatal hyperbilirubinemia (1), the detailed mechanism by which visible light affects bilirubin metabolism in jaundiced newborns is not known. The purpose of this study was to measure the rate of elimination of the principal bilirubin photoproduct, $4 \mathrm{Z}, 15 \mathrm{E}-$ bilirubin, and to determine whether this is sufficient to

Received June 22, 1984; accepted October 3, 1984.

Address correspondence and requests for reprints to John F. Ennever, Ph.D. M.D., Department of Pediatrics, Rainbow Babies and Childrens Hospital, 2101 Adelbert Road, Cleveland, OH 44106.

Supported by the U.S. Public Health service through Grants CA-23692 and Research Career Development Award 1K0-0043 to W.T.S. account for the decline in plasma bilirubin observed during phototherapy.

Bilirubin, derived from the degradation of heme, is a potentially toxic, highly lipophylic molecule. In mammals this pigment is rapidly cleared from the circulation and excreted as a glucuronide conjugate, primarily in the bile (2). Newborn infants commonly develop hyperbilirubinemia due in part to a decreased ability to conjugate bilirubin and an increased pigment load. During phototherapy, the most commonly used treatment for unconjugated hyperbilirubinemia, bilirubin undergoes several reactions (3-7). All of these reactions yield photoproducts which are more polar and therefore presumably more easily excreted than native bilirubin. The fastest photochemical reaction is a $\mathrm{Z}$ to $E$ isomerization reaction $(5,8)$ which in human infants yields primarily the $4 \mathrm{Z}, 15 \mathrm{E}$-bilirubin isomer (6). This reaction is readily reversible and up to $20 \%$ of the total bilirubin can be converted to this isomer during phototherapy (9-12).

Since the quantum yield of the configurational isomerization reaction is at least 40 times greater than that for any other photochemical reaction of bilirubin (8), it has been assumed that the elimination of bilirubin during phototherapy is the result of formation and excretion of this photoproduct. We have used a rapid, quantitative HPLC method (5) to measure the half-life of the configurational isomer in serum of preterm infants undergoing phototherapy. We have found that the rate of elimination of the $4 \mathrm{Z}, 15 \mathrm{E}-\mathrm{bili}$ irubin isomer is much slower than previously reported (13) and cannot account for the decline in serum bilirubin observed in infants treated with phototherapy.

\section{METHODS}

Patients. The study population included six premature infants in our level II nursery with a mean gestational age of $30 \mathrm{wk}$ and a mean birth weight of $1.3 \mathrm{~kg}$. All infants were treated with phototherapy from a bank of eight daylight fluorescent lamps 
housed in a standard canopy. The irradiance in the 400 to 500 $\mathrm{nm}$ spectral region (measured as described below) was approximately $5 \times 10^{-4} \mathrm{~W} / \mathrm{cm}^{2}$ at a distance of $50 \mathrm{~cm}$ from this phototherapy unit. This compares with an ambient light irradiance in the same spectral region between 0.3 and $3 \times 10^{-7} \mathrm{~W} /$ $\mathrm{cm}^{2}$ in the level II nursery. Decisions on the initiation and termination of phototherapy were based on standard clinical criteria. Duration of treatment ranged from 2 to 8 days. Serum bilirubin levels at the end of phototherapy ranged from 6 to 10 $\mathrm{mg} / \mathrm{dl}$. No patient had laboratory evidence of hemolytic disease or hepatic dysfunction and none required an exchange transfusion. At the time of the study, all patients were being fed enterally with human breast milk and/or Special Care Formula (Ross Laboratories, Columbus, $\mathrm{OH}$ ). Prior to enrollment in the study, informed consent was obtained from the patient's parents in accordance with the established guidelines of our Committee on Human Investigation.

Bilirubin analysis. Samples were obtained by heel stick or venipuncture under subdued light and immediately placed in foil-covered tubes; the serum was separated by centrifugation and stored at $-20^{\circ} \mathrm{C}$ until analyzed. For each patient, one serum sample was obtained immediately following the discontinuation of phototherapy; two additional samples were drawn over the next $9 \mathrm{~h}$. A final sample was obtained 12 to $24 \mathrm{~h}$ following cessation of phototherapy. The bilirubin isomer composition of these samples was determined by reversed-phase HPLC on a $0.46 \times 25 \mathrm{~cm}$ Zorbax-ODS column (DuPont Instruments, Wilmington, DE) fitted with a precolumn with $0.1 \mathrm{M}$ di- $n$-octylamine acetate in methanol, $\mathrm{pH} 7.7$ as the eluant (5), using a Varian model 5060 liquid chromatograph equipped with a model UV-100 detector set at $465 \mathrm{~nm}$. Identification of the peaks on the chromatograms was based on chemical and spectroscopic analysis by McDonagh et al. $(5,6)$. Quantitation of peak areas was performed on a Hewlett-Packard model 3390A reporting integrator.

The serum half-life of the configurational isomers for each patient was determined by linear-least squares best fit to semi-

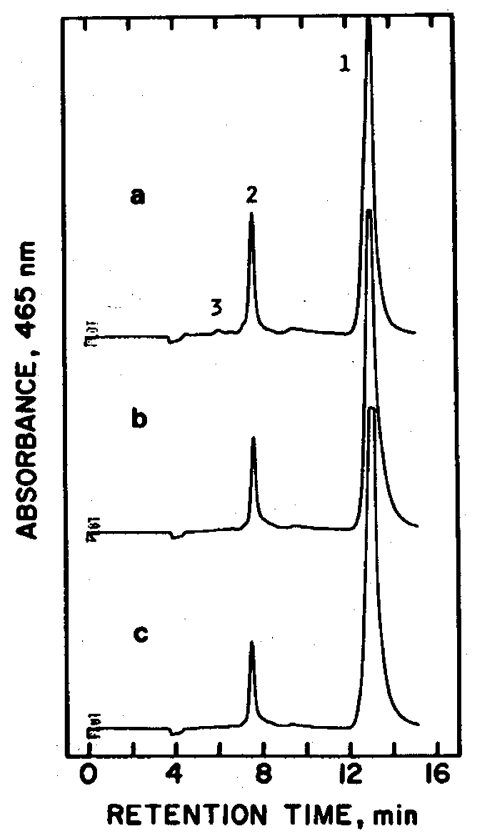

Fig. 1. Chromatographic analysis of serum from an infant following cessation of phototherapy. $a$, HPLC of serum obtained immediately following the end of 6 days of phototherapy. $b$, HPLC of serum drawn 3 $h$ after illumination ended. $c$, HPLC of serum $6 \frac{1 / 2}{h}$ after the end of phototherapy. Peak 1 is native $4 Z, 15 Z$-bilirubin. Peak 2 is the $4 Z, 15 \mathrm{E}$ bilirubin configurational isomer. Peak 3 is the structural isomer, lumirubin.

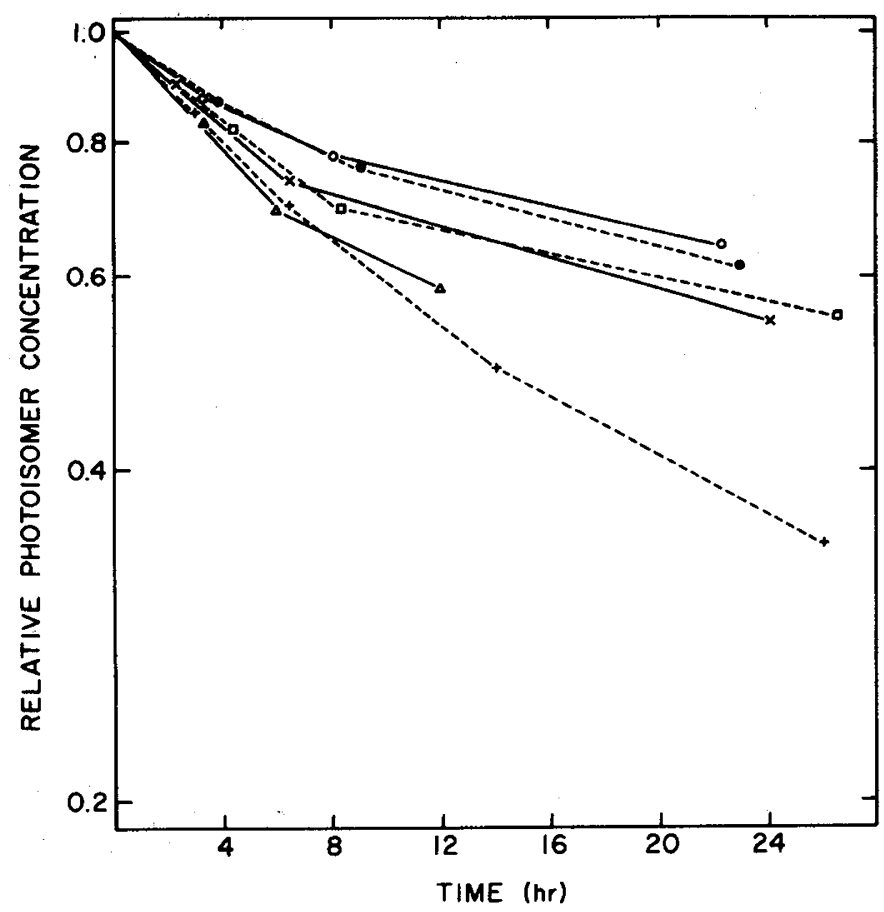

Fig. 2. Decline in serum concentration of bilirubin configurational isomers after cessation of phototherapy. Each symbol represents data from one patient. The photoisomer concentration in the serum, measured by HPLC, was normalized for each patient to 1.0 at the end of phototherapy (time $=0$ ). Serum isomer concentration in subsequent samples are relative to that at time $=0$.

logarithmic plots of the isomer concentration (from the integrated peak areas on the chromatograms) versus time.

The rate of thermal reversion of the configurational isomers to native bilirubin was determined by incubating serum samples (buffered to $\mathrm{pH} 7.4$ by the addition of $0.05 \mathrm{M}$ HEPES) at $37^{\circ} \mathrm{C}$ and monitoring the isomer composition by HPLC over $24 \mathrm{~h}$.

Irradiance measurements. The irradiance of the phototherapy units and of the ambient light in the nursery falling within the bilirubin absorption band ( 400 to $500 \mathrm{~nm}$ ) was measured with an International Light IL700 radiometer and a SEE 400 broadband detector fitted with a filter (type TBLU, International Light, Newburyport, MA) which transmits light between 350 and 530 $\mathrm{nm}$. The peak response of this detector-filter combination is at $468 \mathrm{~nm}$ with half-maximum sensitivity at 397 and $483 \mathrm{~nm}$.

\section{RESULTS}

During phototherapy bilirubin is converted to more polar isomers which achieve steady-state levels in the serum within 3 to $4 \mathrm{~h}$ after the start of phototherapy $(12,14)$. Figure 1 shows a typical HPLC analysis of serum from a patient who had been treated for 6 days with phototherapy. Chromatogram a is of serum obtained as phototherapy was stopped; chromatograms b and $c$ are of samples obtained 3 and $61 / 2 \mathrm{~h}$ later, respectively. The major pigment, peak 1 , is native $4 Z, 15 Z$-bilirubin. Peak 2 is the configurational photoisomer, $4 Z$-15E-bilirubin. A small amount of $4 \mathrm{E}, 15 \mathrm{Z}$-bilirubin is formed in vivo. However, it is not completely resolved from the $4 Z, 15 \mathrm{E}$-isomer and in the chromatogram appears as a shoulder eluting slightly ahead of peak 2 . Peak 3 is the structural isomer lumirubin (6), which has also been called photobilirubin II (15) and cyclobilirubin (16).

Analyses of serum samples following the discontinuation of phototherapy in six premature infants revealed that the concentration of $4 \mathrm{Z}, 15 \mathrm{E}-$ bilirubin declined slowly. Figure 2 contains plots of configurational isomer concentration in the serum as a function of time after the end of phototherapy for these six 
infants. The rate of decline in photoisomer concentration appears to be first-order over the initial 8 to $10 \mathrm{~h}$. After this initial period, the serum concentration of the photoisomer declined even more slowly. The serum half-life for the $4 \mathrm{Z}, 15 \mathrm{E}$-isomer calculated from the initial (more rapid) rate of disappearance ranged from 12 to $21 \mathrm{~h}$, with a mean of $15 \mathrm{~h}$. There was no correlation between the length of phototherapy treatment and rate of decline in configurational isomer concentration. In control experiments, there was negligible reisomerization of the configurational isomer back to native bilirubin in serum samples incubated for $24 \mathrm{~h}$ at $37^{\circ} \mathrm{C}$ in the dark. Therefore, the disappearance of the isomer from the serum was not simply the result of thermal reisomerization.

Lumirubin disappeared from the serum much more quickly than did the configurational isomer. Lumirubin is found in serum during and at the end of phototherapy (Fig. 1a), however, little or none was detectable in any of the serum samples obtained 2 to $3 \mathrm{~h}$ after stopping treatment (Fig. $1 b$ ). These results indicate that the half-life of lumirubin in the serum is less than $2 \mathrm{~h}$, compared to the 12 to $21 \mathrm{~h}$ half-life of the configurational isomer.

\section{DISCUSSION}

Our results confirm previous reports that the principal photochemical reaction occurring in jaundiced infants treated with phototherapy is $\mathrm{Z}$ to $\mathrm{E}$ configurational isomerization of bilirubin $(9-11)$. The rate of disappearance of bilirubin configurational isomers from the serum of preterm infants is very slow. Lamola et al. (13) reported a more rapid elimination of isomer in 3-yrold girl with Crigler Najjar (I) syndrome. The estimate of configurational isomer concentration provided by the fluorescent assay used by these investigators may have been inaccurate because of interference from lumirubin (8). Alternatively, the difference between our data and that of Lamola et al. (13) may indicate that this older child had a faster excretory rate for the configurational isomer than premature infants.

Our interpretation of the slow decline in the serum concentration of $4 \mathrm{Z}, 15 \mathrm{E}$-bilirubin is that this isomer is excreted slowly by preterm infants. It is unlikely that the slow serum decline is either the result of ongoing isomer production after the end of phototherapy, or the result of migration of isomer from an extravascular pool into the circulation to replace excreted pigment. Ongoing production of photoisomer is unlikely to affect our calculated serum half-life for two reasons. First, all of the patients were studied in our level II nursery where the ambient light level is lower than that in the neonatal intensive care unit. Second, even in the intensive care unit, the highest amount of $4 \mathrm{Z}, 15 \mathrm{E}$-isomer produced is $6 \%$ of the total $(12)$. We have calculated the isomer half-life from the initial rate of disappearance which begins with 15 to $20 \%$ of the bilirubin as the configurational isomer. [Ongoing production may be the cause of the slower decline in photoisomer concentration observed after the initial 8 to $10 \mathrm{~h}$ (Fig. 2).]

The migration of isomer from an extravascular pool into the plasma to replace excreted pigment could cause the measured decline in serum concentration to be slower than the rate of excretion. However, only if the rate of migration were slower than the rate of excretion would this migration affect the measurement. Recent studies suggest that equilibration of the $4 \mathrm{Z}, 15 \mathrm{E}$ isomer between sites of formation in the tissues and the plasma is rapid. In premature infants the percentage of the plasma bilirubin which is converted to the configurational isomer approaches the photochemically defined equilibrium value within 3 to $4 \mathrm{~h}$ of the start of phototherapy (12). This observation indicates that the rate of exchange of $4 \mathrm{Z}, 15 \mathrm{E}$-isomer between the tissue pool and the vascular pool is rapid (i.e. a half-life $\sim 2 \mathrm{~h}$ ) compared with the rate of disappearance of isomer from the serum (Fig. 2). Thus the rate of disappearance of the $4 \mathrm{Z}, 15 \mathrm{E}-$ isomer from the serum is a measure of its rate of excretion.

If the secretion of the configurational isomer is as slow as suggested by our measured serum half-life, then the clinical response to phototherapy requires the excretion of other photoproducts. The serum half-life can be used to estimate a maximum rate at which bilirubin can be eliminated by excretion of this isomer. If the plasma concentration of bilirubin is $20 \mathrm{mg} / \mathrm{dl}$ and the hematocrit equal to $50 \%$, the total body load of bilirubin would be $17 \mathrm{mg} / \mathrm{kg}$ body weight $(17,18)$, assuming the blood volume to be $85 \mathrm{ml} / \mathrm{kg}$ body weight. The maximum percentage of the total bilirubin present as the configurational isomer is $20 \%$, therefore only $3.4 \mathrm{mg} / \mathrm{kg}$ of bilirubin are in the excretable pool (half of this pool is intravascular and half extravascular). The configurational isomer is eliminated with first-order kinetics with a half-life of $15 \mathrm{~h}$ (Fig. 2), thus each hour $4.5 \%$ of the pool is excreted. Therefore, if the excretable pool is kept at $3.4 \mathrm{mg} / \mathrm{kg}$ and there is no enterohepatic recirculation of excreted pigment, as much as $3.7 \mathrm{mg} / \mathrm{kg} / 24 \mathrm{~h}$ can be eliminated. Daily production of bilirubin in normal (nonhemolytic) newborn infants is approximately $8.5 \mathrm{mg} / \mathrm{kg} / 24 \mathrm{~h}(19)$. Tan has found a $35 \%$ reduction in serum bilirubin $/ 24 \mathrm{~h}$ with moderate intensity phototherapy (20). For an infant with an initial bilirubin concentration of 20 $\mathrm{mg} / \mathrm{dl}$ this reduction would require excretion of $8.5 \mathrm{mg}$ bilirubin per kg plus all of the daily production for a total of $17 \mathrm{mg} / \mathrm{kg} /$ $24 \mathrm{~h}$. In full-term, nonjaundiced infants elimination of native bilirubin is estimated to be less than $6 \mathrm{mg} / \mathrm{kg} / 24 \mathrm{~h}(19)$. Therefore a typical therapeutic response to phototherapy requires elimination of $11 \mathrm{mg} / \mathrm{kg} / 24 \mathrm{~h}$ of which, at most, $4 \mathrm{mg} / \mathrm{kg} /$ day can be accounted for by excretion of the configurational isomer. It is clear that other mechanisms of bilirubin elimination must occur during phototherapy.

The second fastest photochemical reaction of bilirubin is structural isomerization to lumirubin (6). During phototherapy the serum concentration of lumirubin is lower than the concentration of the configurational isomers: 2 to 6 versus 15 to $20 \%$ of the total serum bilirubin. [Note that in Fig. $1 a$ the peak areas do not reflect the relative concentrations of the bilirubin isomers, because of different molar extinction coefficients at $465 \mathrm{~nm}$ (21).] However, lumirubin is cleared from the serum more rapidly than is the configurational isomer. Because lumirubin has nearly disappeared from the serum by the time of our second blood sample, our data do not allow a precise calculation of its serum half-life, but it must be less than $2 \mathrm{~h}$. Thus, although lumirubin is a minor photoproduct in terms of serum concentration, because of its efficient excretion lumirubin may play a quantitatively important role in the therapeutic response to phototherapy.

In summary, the principal in vivo photochemical reactions of bilirubin are configurational and structural isomerization. In the human infant undergoing phototherapy, the rate determining step in the elimination of unconjugated bilirubin appears not to be the formation of these polar isomers, but rather their elimination. In the premature infant, the elimination of the configurational isomers is too slow to account for the clinically observed decline in serum bilirubin. Lumirubin, which is a minor photoproduct, may be important in vivo because of its rapid excretion. Further studies are required to determine the contribution of lumirubin formation and excretion to the decline in serum bilirubin concentration produced by phototherapy.

Acknowledgments. We thank Mr. Mark Sobel for expert technical assistance and Drs. Richard J. Martin and Fanny Knox Ennever for helpful comments on the manuscript.

\section{REFERENCES}

1. Lewis HM, Campbell RHA, Hambleton G 1982 Use or abuse of phototherapy for physiological jaundice of newborn infants. Lancet 2:408-410

2. Ostrow JD, Jandl JH, Schmid R 1962 The formation of bilirubin from hemoglobin in vivo. J Clin Invest 41:1628-1637

3. Stoll MS, Zenone EA, Ostrow JD, Zarembo JE 1979 Preparation and properties of bilirubin photoisomers. Biochem J 183:139-146

4. Onishi S, Kawade N, Itoh S, Isobe K, Suguiyama S 1980 High-pressure liquid chromatographic analysis of anaerobic photoproducts of bilirubin-IX $\alpha$ in 
vitro and its comparison with photoproducts in vivo. Biochem J 190:527532

5. McDonagh AF, Palma LA, Trull FR, Lightner DA 1982 Phototherapy for neonatal jaundice: Configurational isomers of bilirubin. J Am Chem Soc 104:6865-6867

6. McDonagh AF, Palma LA, Lightner DA 1982 Phototherapy for neonatal jaundice: Stereospecific and regioselective photoisomerization of bilirubin bound to human serum albumin and NMR characterization of intramolecular cyclized photoproducts. J Am Chem Soc 104:6867-6869

7. Lightner DA, Linnane WP III, Ahlfors CE 1984 Bilirubin photooxidation products in the urine of jaundiced infants receiving phototherapy. Pediatr Res 18:696-700

8. Lamola AA, Flores J, Doleiden FH 1982 Quantum yield and equilibrium position of the configurational photoisomerization of bilirubin bound to human serum albumin. Photochem Photobiol 35:649-654

9. Onishi S, Isobe K, Itoh S, Kawade N, Sugiyama S 1980 Demonstration of a geometric isomer of bilirubin-IX $\alpha$ in the serum of a hyperbilirubinaemic newborn infant and the mechanism of jaundice phototherapy. Biochem $J$ 190:533-536

10. Lamola AA, Blumberg WE, McClead R, Fanaroff A 1981 Photoisomerized bilirubin in blood from infants receiving phototherapy. Proc Natl Acad Sci USA 78:1882-1886

11. Ennever JF, Speck WT 1984 Mechanism of action of phototherapy: new concepts. In: Rubaltelli R, Jori G (eds) New Trends in Phototherapy. Plenum Press, New York, pp 187-196
12. Costarino AT, Ennever JF, Baumgart S, Speck WT, Paul M, Polin RA 1985 Bilirubin photoisomerization in premature neonates under low and high dose phototherapy. Pediatrics (in press)

13. Lamola AA, McDonagh AF, Watkins JB $1981 \mathrm{Z} \rightarrow \mathrm{E}$ photoisomerization of bilirubin can account for the phototherapy-associated reduction in serum bilirubin in a Crigler-Najjar (I) patient. Am Soc Photobiol 9:182 (abstr)

14. Ennever JF, Sobel M, McDonagh AF, Speck WT 1984 Phototherapy for neonatal jaundice: in vitro comparison of light sources. Pediatr Res 18:667670

15. Bonnett R, Buckley DG, Hamzetash D, Hawkes GE, Ioannou S, Stoll MS 1984 Photobilirubin II. Biochem J 219:1053-1056

16. Onishi S, Mirua I, Isobe K, Itoh S, Ogino T, Yokoyama T, Yamakawa T 1984 Structure and thermal interconversion of cyclobilirubin IX $\alpha$. Biochem 218:667-676

17. Pearson HA 1967 Life-span of the fetal red blood cell. J Pediatr 70:166-172

18. Ostrow JD, Schmid R 1963 The protein-binding of $C^{14}$-bilirubin in human and murine serum. J Clin Invest 42:1286-1299

19. Maisels MJ, Pathak A, Nelson NM, Nathan DG, Smith CA 1971 Endogenous production of carbon monoxide in normal and erythroblastotic newborn infants. J Clin Invest 50:1-8

20. Tan KL 1982 The pattern of bilirubin response to phototherapy for neonatal hyperbilirubinemia. Pediatr Res 16:670-674

21. Knox 1, Ennever JF, Speck WT 1985 Urinary excretion of an isomer of bilirubin during phototherapy. Pediatr Res 19:198-201

\title{
Circulating Thyrotropin in the Ovine Fetus: Evidence for Pulsatile Release and the Effect of Hypothermia in Utero
}

\author{
MHOYRA FRASER, TANIA R. GUNN, J. H. BUTLER, BARBARA M. JOHNSTON, AND \\ P. D. GLUCKMAN \\ Department of Paediatrics, University of Auckland School of Medicine, Auckland, New Zealand
}

\begin{abstract}
The secretion of thyrotropin (TSH) has been investigated in the chronically catheterized ovine fetus (term 145-150 days). Forty-two random plasma samples from 25 fetuses (86-149 days of gestation) were measured for TSH concentrations by radioimmunoassay. Plasma TSH concentrations were highest in the youngest fetusès [86-110 days, $3.9 \pm$ (SD) $5.5 \mu \mathrm{U} / \mathrm{ml}, n=13$ ]. Thereafter TSH concentrations declined to $0.4 \pm 0.6 \mu \mathrm{U} / \mathrm{ml}(n=13$, $p<0.05$ ) at 130-150 days of gestation. However, serial sampling at 15-20 min intervals for $180 \mathrm{~min}$ from 14 individual fetuses (91-139 days) showed that TSH was secreted in a markedly exaggerated pulsatile manner compared to that observed after birth. The mean amplitude of TSH pulses fell $(p<0.005)$ from $5.9 \pm 8.1 \mu \mathrm{U} / \mathrm{ml}$ in the fetuses to $2.1 \pm 1.1 \mu \mathrm{U} / \mathrm{ml}$ in five neonatal lambs (6-22 days) and to $1.5 \pm 0.4 \mu \mathrm{U} / \mathrm{ml}$ in three adult nonpregnant ewes. The mean pulse frequency for the 14 fetuses was 0.7 \pm 0.3 pulses/h and was reduced $(p<0.001)$ to $0.3 \pm 0.1$ pulses/h in lambs and to $0.3 \pm 0.1$ pulses/h in the ewes. In
\end{abstract}

Received June 6, 1984; accepted October 10, 1984.

Requests for reprints should be addressed to Dr. P. Gluckman, Department of Paediatrics, University of Auckland, Private Bag, Auckland, New Zealand.

This work was supported by grants from the Medical Research Council of New Zealand, The Auckland Medical Research Foundation and the National Children's Health Research Foundation. the neonate, hypothermia is a potent stimulus to TSH release. To examine the ontogeny of this response, the temperature of the fetus in utero (106-127 days of gestation) was lowered by circulating water $\left(14-18^{\circ} \mathrm{C}\right)$ at either a fast or slow rate through a coil placed either externally around the fetus or internally in the fetal esophagus and stomach. The fetuses were cooled for a period of $1 \mathrm{~h}$ during which fetal samples were obtained. In eight fetuses (106127 days), the mean plasma TSH concentration rose ( $p<$ 0.001 ) from $1.5 \pm 1.6 \mu \mathrm{U} / \mathrm{ml}$ to $6.7 \pm 2.1 \mu \mathrm{U} / \mathrm{ml}$ during 1 $h$ of fast external cooling (maximum fetal temperature fall $\left.3.5^{\circ} \mathrm{C}\right)$. Plasma TSH values also rose $(p<0.02)$ during fast internal cooling (maximum temperature fall $1.9^{\circ} \mathrm{C}$ ) from $1.4 \pm 1.9$ to $5.9 \pm 8.2 \mu \mathrm{U} / \mathrm{ml}(n=5,116-132$ days $)$. A slower rate of cooling either externally (temperature fall $1.1^{\circ} \mathrm{C}$ ) or internally (temperature fall $0.9^{\circ} \mathrm{C}$ ) induced a variable response. The marked pulsatility of fetal TSH secretion which decreases after birth is postulated to be a consequence of immature negative feedback by thyroid hormones on fetal TSH release. The presence of a TSH response to hypothermia from 0.7 gestation is evidence that neuroendocrine mechanisms mediating TSH release and hypothalamic thermoregulatory responses have differentiated by this age. (Pediatr Res 19: 208-212, 1985) 